\title{
Letter to the editor on "risk factors for complicated diverticulitis: systematic review and meta-analysis". What is the place of lateral internal partial sphincterotomy in the recurrent colonic diverticulitis treatment?
}

\author{
Ali Naki Yücesoy ${ }^{1}$ \\ Accepted: 15 October 2017 /Published online: 20 October 2017 \\ (C) Springer-Verlag GmbH Germany 2017
}

\section{Dear Editor:}

It was a great pleasure to read the article "Risk factors for complicated diverticulitis: systematic review and metaanalysis" by H. E. Bolkenstein et al. [1]. Colonic diverticulosis (CD) seems to be one of the most common health problems that modern life has brought to humans. Colonic diverticular disease (CDD) can be defined as clinically manifested form of the colonic diverticulosis by bleeding or infecting. Although diverticulitis shows an uncomplicated clinical course in the vast majority of the patients, it can be complicated by perforation, obstruction, and abscess or fistula formation in $25 \%$ of the patients. CDD and its complications represent a significant burden for national health systems. A significant decrease of the diverticulitis recurrences together with more comfortable clinical course in recurrences was observed in our patients under 50 years of age who underwent lateral internal partial sphincterotomy (LIS) for surgical treatment of the chronic anal fissure or hemorrhoid and who had uncomplicated recurrent diverticulitis story in their past. Lateral internal partial sphincterotomy was described for surgical treatment of the chronic anal fissure by Eisenhammer [2]. The main aim of LIS is to reduce the resting anal canal pressure by relaxation of the internal anal sphincteric mus- cle. Internal anal sphincteric muscle derived from endoderm should be considered as an embryological continuation of the bowel wall. This condition suggested that increased resting anal canal pressure may have a role in the etiology of diverticulosis. Anorectal manometric studies in CDD patients have not been carefully analyzed yet. We believe that further studies about anal manometric pressure performed in $\mathrm{CD}$ patients can bring new horizons to $\mathrm{CDD}$ treatment.

\section{Compliance with ethical standards}

Conflict of interest The author declares that there is no conflict of interest.

\section{References}

1. Bolkenstein HE, van de Wall BJM, Consten EJC, Broeders AMJ, Wa D (2017) Risk factors for complicated diverticulitis: systematic review and meta-analysis. Int J Color Dis 32:1375-1383

2. Eisenhammer ST (1959) The evaluation of the internal anal sphincterotomy operation with special reference to anal fissure. Surg Gynecol Obstet 109:583-590
Ali Naki Yücesoy

alinakiyucesoy@gmail.com

General Surgery Department, Batı Bahat Hospital, Atatürk mah. İkitelli cad. No:135 K.Çekmece, Istanbul, Turkey 